\title{
RESULTS OF SURGICAL TREATMENT OF DENERATIVE ARTHROPATHY OF THE ROTATOR CUFF USING HEMIARTHROPLASTY- CTA ${ }^{\circledR}$
}

Rômulo Brasil Filho', Fabiano Rebouças Ribeiro', Antonio Carlos Tenor Junior' ${ }^{1}$, Cantidio Salvador Filardi Filho², Guilherme Barbieri Leme da Costa ${ }^{3}$, Thiago Medeiros Storti ${ }^{3}$, André da Costa Garcia ${ }^{3}$, Hilton Vargas Lutfi ${ }^{3}$

\section{ABSTRACT}

Objective: To assess results of CTA ${ }^{\circledR}$ partial shoulder arthroplasty for treatment of degenerative arthropathy of the rotator cuff. Methods: Between December 2006 and June 2009, 23 shoulders of 23 patients were submitted to $\mathrm{CTA}^{\circledR}$ type partial shoulder arthroplasty for treatment of arthropathy secondary to rotator cuff injury. Post-operative follow up time ranged from 6 to 35 months. Mean age was 74.1 years. Patients were predominantly female, representing $78.3 \%$ of cases. The right limb was affected in 18 patients. All patients had undergone at least 6 months of physiotherapy without improvement of the algetic picture, and being submitted to surgery by the same surgical team. None of the patients had history of surgery on the affected shoulder. The method elected for assessing patients dur- ing post-operative follow up was based on UCLA scoring criteria. Results: Improvement in pain was observed in all patients after arthroplasty. Mean UCLA pain score was 9.22 (ranging from 10 to 8 ). Mean function was 6 (10 to 2). Active frontal flexion was 2.39 (highest score 4 and lowest 0 ). Mean frontal flexion force was 4.09 , maximum was 5 and minimum 3. Mean score on the UCLA was 26.52. 95\% were satisfied with the surgery. Conclusion: $\mathrm{CTA}^{\circledR}$ type partial shoulder arthroplasty produced satisfactory results in the treatment of degenerative arthropathy of the rotator cuff and had a low rate of complications.

Keywords - Arthroplasty; Replacement; Joint Diseases; Rotator Cuff

\section{INTRODUCTION}

Degenerative arthropathy of the rotator cuff consists of collapse of the glenohumeral joint secondary to massive chronic rotator cuff injury. It causes elevation of the humeral head, joint destruction, synovial fluid changes, subchondral cysts, flattening of the greater tubercle, osteophytes, acetabularization of the coracoacromial arch and osteopenia ${ }^{(1-3)}$ (Figure 1). It occurs more frequently among female patients after the age of 60 years, and it manifests with pain, crepitation and diminution of the range of motion ${ }^{(4)}$.

Several hypotheses for explaining the development of arthropathy due to rotator cuff lesions have been put forward. In the rheumatological literature, the term Milwaukee shoulder was introduced to describe a condition presented by four elderly women who had massive rotator cuff injuries, destructive glenohumeral arthritis and recurrent effusion in the shoulder (Geyser sign $)^{(5)}$. The most accepted hypotheses suggest that accumulation of hydroxyapatite crystals inside the capsule, synovium and joint cartilage would allow these crystals to be released into the synovial fluid. The crystals would be phagocytized by synovial cells and would thus accumulate inside them and stimulate the release of proteolytic enzymes, including collagenase and protease. These enzymes would lead to joint, capsule and cuff destruction ${ }^{(5-7)}$.

Neer et $\mathrm{al}^{(3)}$ described a hypothesis for how mechanical and nutritional changes would occur in these

1 - Assistant Physician of the Shoulder Group of the Orthopedics and Traumatology Service, HSPE - IAMSPE - São Paulo, SP, Brazil.

2 - Head of the Shoulder Group of the Orthopedics and Traumatology Service, HSPE - IAMSPE - São Paulo, SP, Brazil.

3 - Intern of the Shoulder Group of the Orthopedics and Traumatology Service, HSPE - IAMSPE - São Paulo, SP, Brazil.

Work carried out at the Orthopedics and Traumatology Service of the Hospital do Servidor Público Estadual Francisco Morato de Oliveira - IAMSPE - São Paulo. Correspondence: Rua Pedro de Toledo, 1800 - CEP 04029-000 - São Paulo, SP - E-mail: thiago_storti@hotmail.com

Received for publication: 12/07/2010, accepted for publication: 07/14/2011 
patients. Loss of the dynamic stabilizers of the glenohumeral joint would lead to repeated trauma on the joint surface, thus causing cartilage loss. Furthermore, loss of closed joint space would lead to poor nutrient diffusion to the joint cartilage. Secondarily to shoulder disuse, the subchondral bone would then become more osteoporotic, thus resulting in erosion of the humeral head and completing the development of arthropathy.

The arthropathy classification most used is the system described by Seebauer ${ }^{(8)}$ (Box 1). It assesses the integrity of the anterior shoulder stabilizers and coracoacromial arch, the presence of dynamic stability and the upwards migration of the humeral head. In stage IA, the head is centered on the glenoid; in IB, the head migrates medially in relation to the glenoid; in IIA, the humeral head migrates upwards, but is stabilized by the coracoacromial arch; and in IIB, the humeral head migrates forwards and upwards.

Conservative treatment is initially administered to all patients, using physiotherapy and analgesics. When there is no improvement of the pain and/or range of motion, surgical procedures are $\operatorname{chosen}^{(9,10)}$.

Arthroscopic debridement is an alternative when the patient's main complaint is pain, and consists of joint and bursa cleaning, tuberculoplasty and tenotomy of the biceps. The result may be a transitory improvement of pain, without interfering with the range of motion, but with frequent recurrences over the first two years ${ }^{(10,11)}$.



Figure 1 - Anteroposterior radiograph on a shoulder with arthropathy due to a rotator cuff injury.
The options for replacement arthroplasty are CTA ${ }^{\circledR}$ (cuff tear arthroplasty) and a reverse prosthesis. CTA ${ }^{\circledR}$ prostheses (Figure 2) are used when the arthropathy has not compromised the stability of the glenohumeral joint, the glenoid erosion is only partial and the coracoacromial arch is complete. These are partial prostheses, with a larger humeral head so that there is greater contact with the coracoacromial arch, thus enabling better lever-arm action by the deltoid muscle on arm elevation movements. A reverse prosthesis is used when there is no stability in the glenohumeral joint and the glenoid anatomy is compromised. It is characterized by modification of the center of glenohumeral rotation medially and distally, through positioning the glenoid component (glenosphere) with the aim of boosting the acting of the deltoid muscle ${ }^{(9)}$.

The aim of the present study was to assess the results obtained from CTA ${ }^{\circledR}$ partial shoulder arthroplasty to treat degenerative arthroplasty of the rotator cuff.

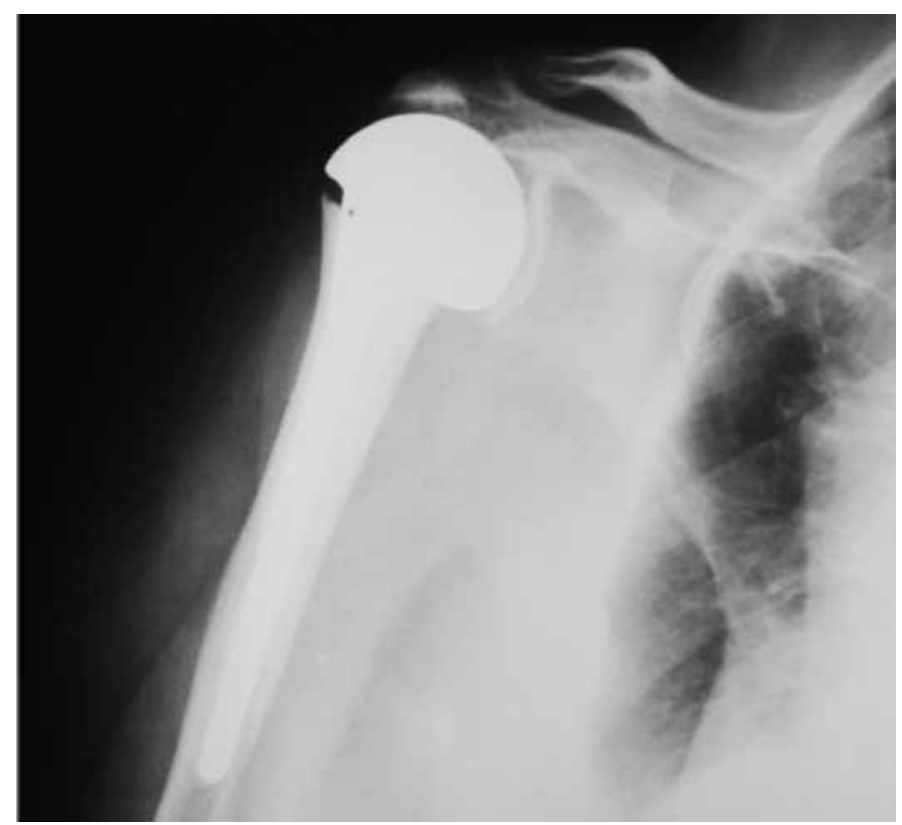

Figure 2 - Postoperative radiography on a shoulder, showing $\mathrm{CTA}^{\circledR}$ hemiarthroplasty.

\section{METHODS}

Between December 2006 and June 2009, 23 shoulders of 23 patients underwent $\mathrm{CTA}^{\circledR}$ partial shoulder arthroplasty to treat degenerative arthroplasty of the rotator cuff. All the patients were operated by the same surgical team from the Shoulder and Elbow Group of the Orthopedics and Traumatology Service at the Public Servants' Hospital of the State of São Paulo, and the access route used was deltopectoral. The length of the postoperative follow-up ranged from 6 to 35 months, with a mean of 20 months. The 
Box 1 - Seebauer ${ }^{(8)}$ classification.

\begin{tabular}{|c|c|c|c|}
\hline Type 1a & Type 1b & Type 2a & Type $2 b$ \\
\hline Anterior structure intact & Anterior structure intact & Compromised & Incompetent \\
\hline Minimal upwards migration & Minimal upwards migration & Upwards & Forwards and upwards \\
\hline Femoralization & Femoralization & Minimal & None \\
\hline Mechanical stabilization & Abnormal & Insufficient & None \\
\hline Acetabularization & Glenoid erosion & Glenoid and humeral erosion & None \\
\hline
\end{tabular}

patients' mean age was 74.1 years, ranging from 62 to 84 years. Females predominated, accounting for $78.3 \%$ of the cases (18 patients). The dominant limb was affected in 18 patients and the non-dominant limb in five patients (Table 1).

Out of the 23 patients evaluated before the operation, five were classified as type IA, nine as type IB and the remaining nine as type IIA. There were no cases of type IIB (Figure 3 ).

All the patients had previously undergone physiotherapy for at least six months, without improvement of their painful condition, and they all had a clinical and imaging diagnosis (radiographs and nuclear magnetic resonance) of degenerative arthropathy of the rotator cuff.

The inclusion criterion was that the patients should be symptomatic, with a Seebauer classification of IA, IB or IIA, who had not improved with rehabilitation treatment administered for a minimum of six months. The following were taken to be exclusion criteria: degenerative arthropathy of the rotator cuff that improved with clinical treatment; previous surgery or neurological lesions in the affected limb; arthropathy classified as Seebauer IIB; and insufficiency of the deltoid muscle.

The clinical assessment on the results was done using the scoring defined by the University of California at Los Angeles (UCLA), as modified by Ellman and $\mathrm{Kay}^{(12)}$, which uses objective and subjective criteria, attributing points according to the pain, degree of mobility, shoulder function, strength and patient satisfaction. The maximum score is 35 points. To measure the degree of joint range of motion, the method described by the American Academy of Orthopedic Surgeons was used $^{(13)}$. To compare the pre and postoperative results regarding UCLA and the orthopedic physical examination with range of motion (OPE), the nonparametric Wilcoxon test was used ${ }^{(14)}$. The rejection level for the nullity hypothesis was 0.05 (significance level of 95\%).

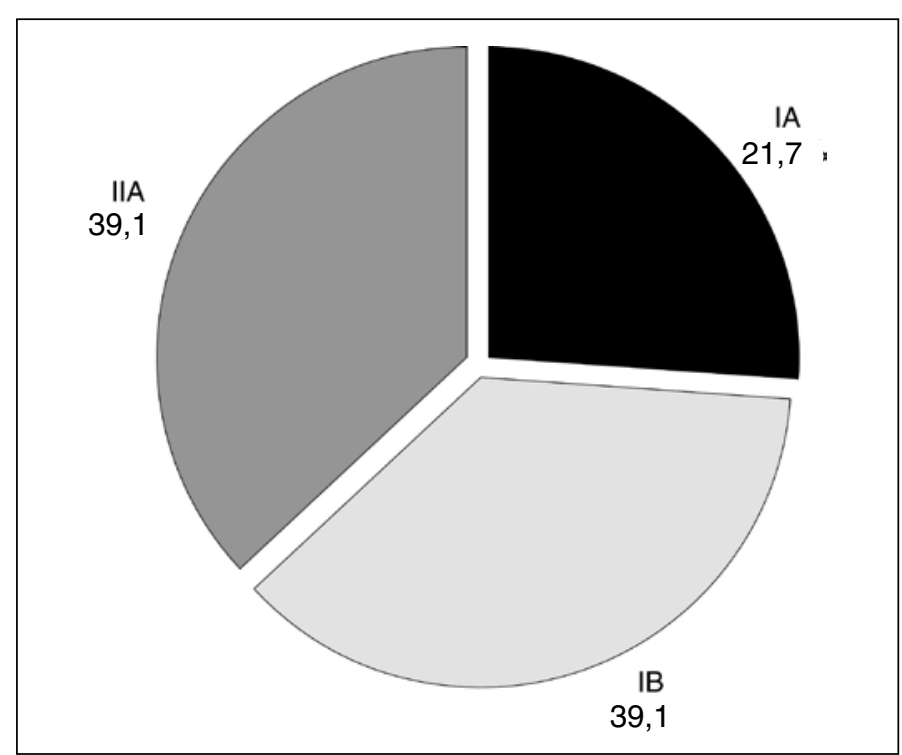

Figure 3 - Distribution of the 23 patients according to the Seebauer classification. 


\section{RESULTS}

It was observed that there was a significant increase in the mean UCLA score, from 10.39 points before the operation to 26.52 points after the operation (Figure 4). The result was considered to be good in the cases of nine patients $(39.1 \%)$, fair in thirteen $(56.6 \%)$ and poor in one $(4.3 \%)$.

With regard to joint range of motion measurements, there was an increase in mean active elevation, from $57.61^{\circ}$ before the operation to $77.83^{\circ}$ after the operation (Figure 5 and Table 2).

The lateral rotation increased from $19.78^{\circ}$ before the operation to $26.09^{\circ}$ after the operation (Figure 6 and Table 2).

The mean medial rotation did not present any change and remained at the level of the third lum- bar vertebra (L3) from before to after the operation (Table 1).

It was observed that all the patients' pain improved after arthroplasty, in relation to their preoperative pain. The mean score on the UCLA table relating to pain was 9.22 , with maximum of 10 and minimum of 8 . Regarding function, the mean was 6 , the maximum was 10 and the minimum was 2 . For active frontal flexion among these patients, the mean was 2.39 , the maximum was 4 and the minimum was 0 . Regarding the strength of frontal flexion, the mean was 4.09 , the maximum was 5 and the minimum was 3 (Figure 7 and Table 3).

Twenty-two of the 23 patients $(95 \%)$ were satisfied with the surgery. The patient who presented the lowest score on the UCLA scale (15 points) and was not satisfied with the surgery presented atrophy of

Table 1. Data on patients.

\begin{tabular}{|c|c|c|c|c|c|c|c|c|c|}
\hline Patient No. & Sex & Age & Side & $\begin{array}{l}\text { Length of time } \\
\text { with disease } \\
\text { (years) }\end{array}$ & $\begin{array}{l}\text { UCLA before } \\
\text { operation }\end{array}$ & Final UCLA & $\begin{array}{c}\text { Seebauer } \\
\text { classification }\end{array}$ & $\begin{array}{c}\text { Pre-op OPE } \\
\text { (Elev, Rext. } \\
\text { Rint) }\end{array}$ & $\begin{array}{c}\text { Post-op OPE } \\
\text { (Elev, Rext. } \\
\text { Rint) }\end{array}$ \\
\hline 1 & $\mathrm{~F}$ & 80 & $\mathrm{D}$ & 4 & $(2+4+3+4+0) 13$ & $(10+8+4+4+5) 31$ & IB & $90 ; 30 ; \mathrm{L} 1$ & $120 ; 40 ; S 1$ \\
\hline 2 & $\mathrm{~F}$ & 76 & $\mathrm{D}$ & 5 & $(2+2+1+4+0) 9$ & $(8+6+2+5+5) 26$ & IB & $40 ; 20 ; \mathrm{L} 5$ & 70;25;L2 \\
\hline 3 & $\mathrm{M}$ & 82 & $\mathrm{D}$ & 6 & $(1+2+1+3+0) 7$ & $(10+2+0+3+0) 15$ & $\| A$ & $30 ; 10 ; \mathrm{S} 1$ & $15 ; 10 ; S 1$ \\
\hline 4 & $\mathrm{~F}$ & 75 & $\mathrm{D}$ & 3 & $(2+4+3+3+0) 12$ & $(10+10+4+4+5) 33$ & $\mathrm{IA}$ & $90 ; 20 ; \mathrm{T} 12$ & 130;30;T10 \\
\hline 5 & $\mathrm{~F}$ & 80 & $\mathrm{D}$ & 5 & $(2+2+1+3+0) 8$ & $(10+6+2+4+5) 27$ & IB & $35 ; 15 ; \mathrm{L} 5$ & $60 ; 20 ; \mathrm{L} 1$ \\
\hline 6 & $\mathrm{~F}$ & 62 & ND & 6 & $(2+4+3+4+0) 13$ & $(10+8+4+4+5) 31$ & $\mathrm{IA}$ & 100;30;L1 & 120;40;L3 \\
\hline 7 & M & 72 & $\mathrm{D}$ & 8 & $(2+2+2+3+0) 9$ & $(8+6+3+3+5) 25$ & IIA & $60 ; 25 ; \mathrm{L} 5$ & $90 ; 30 ;$ L5 \\
\hline 8 & $M$ & 74 & ND & 4 & $(2+4+3+3+0) 12$ & $(10+6+3+4+5) 28$ & IA & $100 ; 30 ; \mathrm{L} 1$ & $90 ; 40 ;$ L3 \\
\hline 9 & $\mathrm{~F}$ & 80 & $\mathrm{D}$ & 7 & $(2+2+2+4+0) 10$ & $(10+6+2+4+5) 27$ & $\| A$ & $50 ; 20 ; \mathrm{L3}$ & $60 ; 20 ;$ L3 \\
\hline 10 & $\mathrm{~F}$ & 73 & $\mathrm{D}$ & 6 & $(2+4+3+4+0) 13$ & $(10+6+3+4+5) 28$ & IB & $90 ; 20 ; T 7$ & $100 ; 25 ; T 12$ \\
\hline 11 & $\mathrm{~F}$ & 70 & D & 4 & $(2+2+1+3+0) 8$ & $(10+4+2+3+5) 24$ & IIA & $30 ; 10 ; S 1$ & 45;20;L5 \\
\hline 12 & $\mathrm{~F}$ & 84 & $\mathrm{D}$ & 7 & $(2+2+0+3+0) 7$ & $(8+6+1+4+5) 24$ & IIA & 20;10;TROC & 30;10;TROC \\
\hline 13 & $\mathrm{~F}$ & 67 & $\mathrm{D}$ & 6 & $(2+2+2+4+0) 10$ & $(8+6+3+5+5) 27$ & IB & $70 ; 30 ; \mathrm{L} 1$ & 100;30;T12 \\
\hline 14 & $\mathrm{~F}$ & 73 & ND & 9 & $(2+4+1+4+0) 11$ & $(8+6+1+5+5) 25$ & $\| A$ & 40;05;L5 & $30 ; 10 ; S 1$ \\
\hline 15 & $M$ & 75 & $\mathrm{D}$ & 3 & $(2+4+3+4+0) 13$ & $(10+6+3+4+5) 28$ & IB & 100;30;L1 & $120 ; 35 ; \mathrm{L} 1$ \\
\hline 16 & $\mathrm{~F}$ & 73 & ND & 6 & $(2+4+2+3+0) 11$ & $(8+8+3+4+5) 28$ & IIA & $60 ; 20 ; S 1$ & $100 ; 40 ; \mathrm{L} 4$ \\
\hline 17 & $\mathrm{M}$ & 78 & $\mathrm{D}$ & 3 & $(2+2+1+4+0) 9$ & $(8+6+1+5+5) 25$ & IB & $30 ; 10 ; S 1$ & $40 ; 15 ; S 1$ \\
\hline 18 & $\mathrm{~F}$ & 80 & $\mathrm{D}$ & 8 & $(2+2+2+4+0) 10$ & $(10+6+2+4+5) 27$ & $\mathrm{IA}$ & 50;20;T10 & 70;35;L1 \\
\hline 19 & $\mathrm{~F}$ & 70 & $\mathrm{D}$ & 4 & $(2+4+3+4+0) 13$ & $(10+6+3+4+5) 28$ & $\mathrm{IA}$ & 120;30;L1 & 100;30;T12 \\
\hline 20 & $\mathrm{~F}$ & 67 & ND & 3 & $(2+2+0+4+0) 8$ & $(8+6+1+5+5) 25$ & $\| A$ & 20;0;TROC & $40 ; 10 ; S 1$ \\
\hline 21 & $\mathrm{~F}$ & 65 & $\mathrm{D}$ & 4 & $(2+4+3+4+0) 13$ & $(10+6+3+4+5) 28$ & IB & $90 ; 40 ; T 10$ & $100 ; 45 ; \mathrm{L} 1$ \\
\hline 22 & $\mathrm{~F}$ & 71 & $\mathrm{D}$ & 6 & $(2+2+2+5+0) 11$ & $(8+4+3+5+5) 25$ & IB & 60;20;L5 & $100 ; 30 ; \mathrm{L} 2$ \\
\hline 23 & $\mathrm{~F}$ & 79 & $\mathrm{D}$ & 8 & $(2+2+1+4+0) 9$ & $(10+4+2+4+5) 25$ & IIA & 40;10;L5 & $60 ; 10 ; S 1$ \\
\hline
\end{tabular}




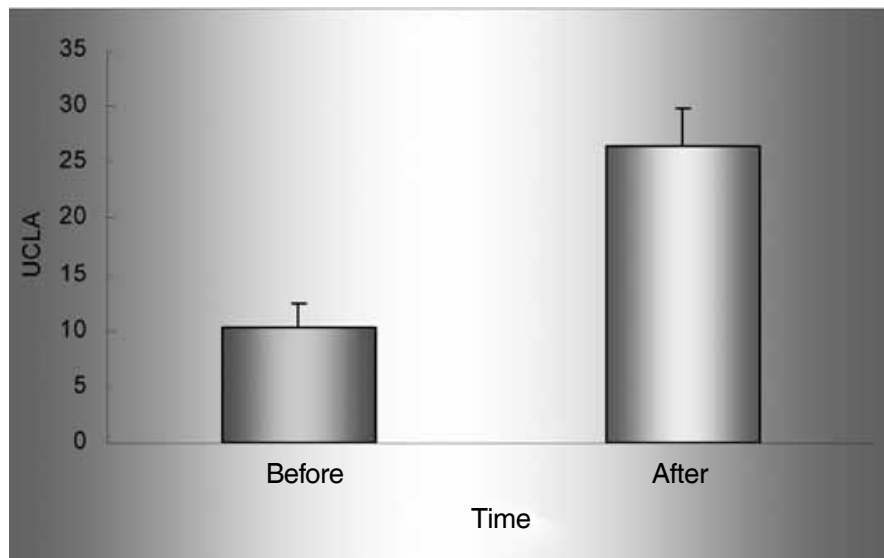

Figure 4 - Mean and standard deviation of the UCLA scores before and after the operation.

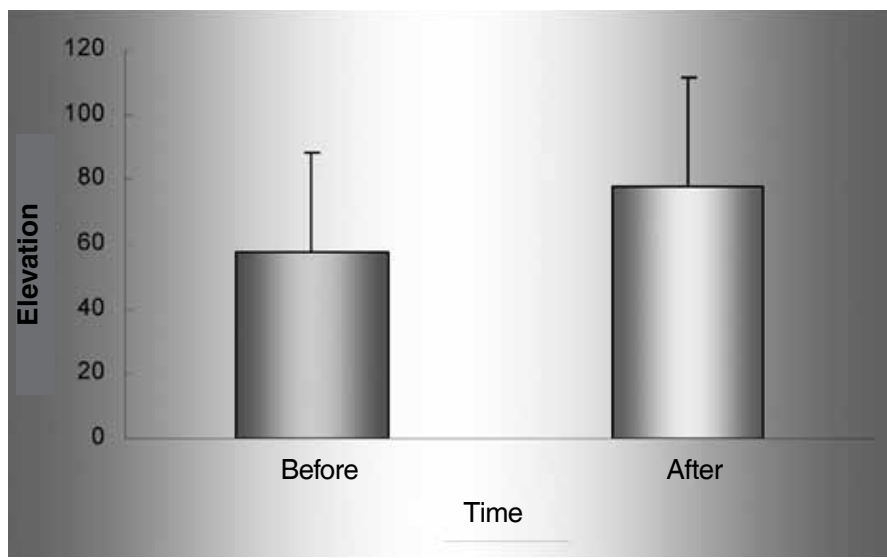

Figure $\mathbf{5}$ - Mean and standard deviation of the elevation before and after the operation.



Figure 6 - Mean and standard deviation of the lateral rotation before and after the operation.



Figure 7. Mean and standard deviation of the UCLA scores before and after the operation.

Table 2 - Elevation and external rotation values at the times evaluated.

\begin{tabular}{c|c|c|c|c|c|c|c|c}
\hline Variable & Time & $\mathbf{n}$ & Mean & SD & Median & Minimum & Maximum & $\mathbf{p}^{*}$ \\
\hline Elevation & Before & 23 & 57.61 & 30.74 & 50 & 10 & 120 \\
\hline & After & 23 & 77.83 & 33.60 & 90 & 15 & 130 \\
\hline & & & & & & & \\
\hline External & Before & 23 & 19.78 & 9.94 & 20 & 0 & 40 \\
\hline rotation & After & 23 & 26.09 & 11.48 & 30 & 10 & 45 \\
\hline
\end{tabular}

$\left(^{\star}\right)$ descriptive probability level from the nonparametric Wilcoxon test

the deltoid muscle, although his electroneuromyography result was normal. There was no case of prosthesis dislocation, infection or neurovascular deficit in the operated limb.

\section{DISCUSSION}

$\mathrm{CTA}^{\circledR}$ arthroplasty is used when the arthropathy has not compromised the anterosuperior stability of the glenohumeral joint, with partial erosion of the glenoid and a complete coracoacromial arch. This is a partial prosthesis with a humeral head that extends as far as the greater tuberosity, in order to provide contact with the coracoacromial arch, thereby enabling lever-arm improvement of the deltoid muscle in arm elevation movements.

Visotsky et $\mathrm{al}^{(2)}$ found that $89 \%$ of their results were satisfactory, through using conventional partial arthroplasty for treating patients classified as Seebauer IA, 
Table 3. Domain values for UCLA scores at the times evaluated.

\begin{tabular}{|c|c|c|c|c|c|c|c|c|c|}
\hline \multicolumn{2}{|c|}{ Domain } & Time & $\mathbf{N}$ & Mean & SD & Median & Minimum & Maximum & $\mathbf{p}^{*}$ \\
\hline \multicolumn{2}{|c|}{ Pain } & Before & 23 & 1.96 & 0.21 & 2 & 1 & 2 & $<0.001$ \\
\hline & & After & 23 & 9.22 & 1.00 & 10 & 8 & 10 & \\
\hline \multicolumn{2}{|c|}{ Function } & Before & 23 & 2.87 & 1.01 & 2 & 2 & 4 & $<0.001$ \\
\hline & & After & 23 & 6.00 & 1.60 & 6 & 2 & 10 & \\
\hline \multicolumn{2}{|c|}{ Active } & Before & 23 & 1.87 & 1.01 & 2 & 0 & 3 & 0.001 \\
\hline flexion & After & 23 & 2.39 & 1.08 & 3 & 0 & 4 & & \\
\hline Flexion & Before & 23 & 3.70 & 0.56 & 4 & 3 & 5 & 0.003 & \\
\hline strength & After & 23 & 4.09 & 0.60 & 4 & 3 & 5 & & \\
\hline \multirow[t]{2}{*}{ Satisfaction } & Before & 23 & 0.00 & 0.00 & 0 & 0 & 0 & $<0.001$ & \\
\hline & After & 23 & 4.78 & 1.04 & 5 & 0 & 5 & & \\
\hline
\end{tabular}

$\left({ }^{\star}\right)$ descriptive probability level from the nonparametric Wilcoxon test

IB and IIA. They achieved improvements in pain, elevation and lateral rotation of the shoulder. Like in our study, they did not include patients classified as Seebauer IIB. In our sample, we observed that only one case (patient no. 3; classified as type IIA) presented an unsatisfactory result. This patient achieved an improvement in pain, but with worsening of elevation movement, and was dissatisfied with the limitation on joint range of motion that was obtained. This patient also presented atrophy of the deltoid muscle, although the electroneuromyography result was normal.

Zuckerman et $\mathrm{al}^{(15)}$ used the postoperative evaluation method based on the UCLA criteria to evaluate conventional partial arthroplasty, and obtained a mean of 22 points, with a mean range of motion of $86^{\circ}$ of active elevation and $29^{\circ}$ of active lateral rotation. They reported that $87 \%$ of the patients were satisfied in relation to improvement of pain. In our sample, the results obtained from CTA ${ }^{\circledR}$ partial shoulder arthroplasty presented a mean of 26.52 points and a satisfaction rate of $92.2 \%$ in relation to pain improvement (Table 1).

In our study, we used rigid exclusion criteria, which we believe to be very important for favorable results from $\mathrm{CTA}^{\circledR}$ arthroplasty. $\mathrm{CTA}^{\circledR}$ hemiarthroplasty requires anterior stabilizers to impede anterior subluxation of the prosthesis: this role is played by the coracoacromial arch and the subscapular muscle.
In addition, a functioning motor is required, such as the deltoid muscle, along with a complete axillary nerve. Field et al ${ }^{(16)}$ evaluated 16 patients who underwent hemiarthroplasty to treat arthropathy due to rotator cuff injury, and found that four of the six patients with unsatisfactory results had undergone previous acromioplasty, with release of the coracoacromial ligament. They concluded that coracoacromial arch competence and deltoid muscle function are important components for the stability of hemiarthroplasty, when performed to treat arthropathy due to cuff injuries.

The studies by Zuckerman et $\mathrm{al}^{(15)}$ and SanchezSotelo et $\mathrm{al}^{(17)}$ showed that hemiarthroplasty provides adequate pain improvements but only moderate gains in functional range of motion, in patients with arthropathy due to cuff injuries. On the other hand, in relation to the Delta ${ }^{\circledR}$ reverse prosthesis, studies $^{(18-21)}$ have shown better gains in active range of movement, which leads to functional improvement in these patients. However, the complication rates remain relatively high $(>17 \%)$, and studies with longer follow-up and greater experience with these implants are still necessary.

\section{CONCLUSION}

$\mathrm{CTA}^{\circledR}$ partial shoulder arthroplasty has satisfactory results when used to treat degenerative rotator cuff arthropathy, with a low complication rate. 


\section{REFERENCES}

1. Hamada K, Fukuda H, Mikasa M, Kobayashi $\mathrm{Y}$. Roentgenographic findings in massive rotator cuff tears. A long-term observation. Clin Orthop Relat Res. 1990;(254):92-6.

2. Visotsky JL, Basamania C, Seebauer L, Rockwood CA, Jensen KL. Cuff tear arthropathy: pathogenesis, classification, and algorithm for treatment. J Bone Joint Surg Am. 2004;86(Suppl 2):35-40.

3. Neer CS, Craig EV, Fukuda H. Cuff-tear arthropathy. J Bone Joint Surg Am. 1983;65(9):1232-44.

4. Pollock RG, Deliz ED, Mcllveen SJ, Flatow EL, Bigliani LU. Prosthetic replacement in rotator cuff-deficient shoulders. J Shoulder Elbow Surg. 1992;1(4):173-86.

5. Garancis JC, Cheung HS, Halverson PB, McCarty DJ. "Milwaukee shoulder" - association of microspheroids containing hydroxyapatite crystals, active collagenase, ad neutral protease with rotator cuff defects. III. Morphologic and biochemical studies of an excised synovium showing chondromatosis. Arthritis Rheum. 1981;24(3):484-91.

6. Halverson PB, Cheung HS, McCarty DJ, Garancis J, Mandel N. "Milwaukee shoulder" - association of microspheroids containing hydroxyapatite crystals, active collagenase, ad neutral protease with rotator cuff defects. II. Synovial fluid studies. Arthritis Rheum. 1981;24(3):474-83.

7. McCarty DJ, Halverson PB, Carrera GF, Brewer BJ, Kozin F. "Milwaukee shoulder" association of microspheroids containing hydroxyapatite crystals, active collagenase, and neutral protease with rotator cuff defects. I. Clinical aspects. Arthritis Rheum. 1981;24(3):464-73.

8. Seebauer L. Biomecanical classification of cuff tear arthropaty [abstract]. In Global Shoulder Society Meeting; 2003 July 17-19 Salt Lake City, UT-USA.

9. Arntz CT Jackins S, Matsen FA. Prosthetic replacement of the shoulder for the treatment of defects in the rotator cuff and the surface of the glenohumeral joint. Bone Joint Surg Am. 1993;75:485-91.

10. Boileau P, Sinnerton RJ, Chuinard C, Walsh G. Arthroplasty of the shoulder. J Bone Joint Surg Br. 2006;88(5):562-75.
11. Walch G, Madonia G, Pozzi I, Riand N, Levigne C. Arthroscopic tenotomy of the tendon of the long head of the biceps in rotator cuff ruptures. Amsterdam: Elsevier; 1997. p.350-5.

12. Ellman $\mathrm{H}$, Kay SP. Arthroscopic subacromial decompression for chronic impingement. Two- to five-year results. J Bone Joint Surg Br. 1991;73(3):395-8

13. Hawkins RJ, Bokor DJ. Clinical evaluation of shoulder problems. In: Rockwood CA, Matsen FA, editors. The shoulder. 2nd ed. Saint Louis: W.B. Saunders; 1998. p.164-98.

14. Rosner B. Fundamentals of Biostatistics. 2nd ed. Boston: PWS Publishers; 1986. $584 p$.

15. Zuckerman JD, Scott AJ, Gallagher MA. Hemiarthroplasty for cuff tear arthropathy. J Shoulder Elbow Surg. 2000;9(3):169-72.

16. Field LD, Dines DM, Zabinski SJ, Warren RF. Hemiarthroplasty of the shoulder for rotator cuff arthropathy. J Shoulder Elbow Surg. 1997;6(1):18-23.

17. Sanchez-Sotelo J, Cofield RH, Rowland CM. Shoulder hemiarthroplasty for glenohumeral arthritis associated with severe rotator cuff deficiency. J Bone Joint Surg Am. 2001;83(12):1814-22.

18. Boileau P, Watkinson DJ, Hatzidakis AM, Balg F. Grammont reverse prosthesis: design, rationale, and biomechanics. J Shoulder Elbow Surg. 2005;14(1 Suppl S):147S-61S.

19. De Buttet M, Bouchon Y, Capon D, Delfosse J. Grammont shoulder arthroplasty for osteoarthritis with massive rotator tears-report of 71 cases [abstract]. J Shoulder Elbow Surg. 1997; 6:197.

20. Rittmeister M, Kerschbaumer F. Grammont reverse total shoulder arthroplasty in patients with rheumatoid arthritis and nonreconstructible rotator cuff lesions. J Shoulder Elbow Surg. 2001;10(1):7-22.

21. Sirveaux F, Favard L, Oudet D, Huquet D, Walch G, Mole D. Grammont inverted total shoulder arthroplasty in the treatment of glenohumeral osteoarthritis with massive rupture of the cuff: Results of a multicentre study of 80 shoulders. $J$ Bone Joint Surg Br. 2004;86(3):388-95. 